\title{
Modelo f @ r: Reflexión Conjunta Realizada por Docentes que Enseñan Matemáticas después de un Proceso de Capacitación con Tecnologías
}

\author{
Fábio Douglas Farias \\ prof.fabiodouglas@gmail.com \\ https://orcid.org/0000-0002-5237-4536 \\ Universidade Cidade de São Paulo (UNICID) \\ São Paulo, Brasil. \\ Douglas da Silva Tinti \\ tinti@ufop.edu.br \\ http://orcid.org/0000-0001-8332-5414 \\ Universidade Federal de Ouro Preto (UFOP) \\ Ouro Preto, Brasil. \\ Ana Lúcia Manrique \\ analuciamanrique@gmail.com \\ http://orcid.org/0000-0002-7642-0381 \\ Pontifícia Universidade Católica de São Paulo (PUC-SP) \\ São Paulo, Brasil.
}

Recibido: 03/04/2020 Aceptado: 22/05/2020

\begin{abstract}
Resumen
El presente artículo es fruto de una investigación del tipo observación participante y tiene por objetivo identificar, a partir de reflexiones presentadas por profesoras que enseñan matemáticas en la escuela primaria, contribuciones de un proceso formativo pautado en un modelo enfocado en el uso de softwares educativos. El modelo f@r (Formación-Acción-Reflexión) propuesto por Costa (2012) concibe cinco etapas, a saber: visión, plan, práctica, interacción y reflexión. Para alcanzar el objetivo propuesto para el presente artículo, analizamos los discursos de cinco profesoras, participantes de los encuentros de formación, recogidas por medio de grabaciones en audio y video de dos encuentros que componen la etapa de reflexión propuesta por el modelo f@r. Los resultados mostraron que el contexto establecido por ese proceso de formación propuesto posibilitó que cada una de las profesoras, en diferentes niveles, desarrollara al mismo tiempo, lo que sabían sobre tecnologías, sobre las estrategias pedagógicas y sobre el conocimiento de determinado contenido matemático

Palabras clave: Formación de profesores. Modelo f @ r. Conocimiento tecnológico y pedagógico del contenido (TPACK). Softwares Educativos.

\section{Modelo f@r: reflexão conjunta realizada por professores que ensinam matemática após um processo formativo com tecnologias}

\section{Resumo}

O presente artigo é fruto de uma pesquisa do tipo observação participante e tem por objetivo identificar, a partir de reflexões apresentadas por professoras que ensinam matemática nos anos iniciais do ensino fundamental, contribuições de um processo formativo pautado em um modelo focado no uso de softwares educativos. O modelo f@r (Formação-Ação-Reflexão) proposto por
\end{abstract}


Costa (2012) concebe cinco etapas, a saber: visão, plano, prática, interação e reflexão. Para atingirmos o objetivo proposto para o presente artigo, analisamos as falas de cinco professoras, participantes dos encontros de formação, coletadas por meio de gravações em áudio e vídeo de dois encontros que compõem a etapa de reflexão proposta pelo modelo. Os resultados mostraram que o contexto estabelecido por esse processo de formação proposto possibilitou que cada uma das professoras, em diferentes níveis, desenvolvesse em simultâneo, o que sabiam sobre tecnologias, sobre as estratégias pedagógicas e sobre o conhecimento de determinado conteúdo matemático.

Palavras-chave: Formação de Professores. Modelo f@r. Conhecimento Tecnológico e Pedagógico do Conteúdo (TPACK). Softwares Educativos.

\title{
F@r model: joint reflection of teachers who teach mathematics after a formative process with technologies
}

\begin{abstract}
This article is the result of a research of the type participant observation and aims to identify, from reflections presented by teachers who teach mathematics in the initial years of elementary school, contributions of a formative process based on a model focused on the use educational software. The f@r model (Formation-Action-Reflection) proposed by Costa (2012) conceives five stages, namely: vision, plan, practice, interaction and reflection. In order to reach the objective proposed for this article, we analyze the statements of five teachers, participants in the training meetings, collected through audio and video recordings of two meetings that make up the reflection stage proposed by the model. The results showed that the context established by this proposed training process allowed each of the teachers, at different levels, to simultaneously develop what they knew about technologies, pedagogical strategies and knowledge of a certain mathematical content.

Keywords: Teacher Education. f@r Model. Technological and Pedagogical Knowledge of Content (TPACK). Educational Software.
\end{abstract}

\section{Introdução}

Para viver na sociedade atual é exigido dos indivíduos que nela atuam o constante desenvolvimento de novas habilidades e competências. Cada cultura, a sua maneira, está imersa em um contexto tecnológico e exponencialmente dinâmico no qual a capacidade de utilizar as informações criticamente é fundamental para uma convivência autônoma e para tomada de decisões. É fato que vivemos em uma sociedade na qual, a todo instante, somos munidos de informações pelos diversos canais de comunicação e, claro, pelos diversos meios tecnológicos.

Contudo, em um entendimento mais generalizado, podemos dizer que a informação por si só não constitui conhecimento. Isto é, o indivíduo, por meio da construção de conhecimentos e o desenvolvimento de habilidades e competências ao longo da sua experiência de vida e potencializado por um processo de escolarização, é quem dá significado às informações. E essas 
informações já podem ser obtidas por meio das atuais Tecnologias da Informação e Comunicação (TICs), por exemplo, computadores, tablets e smartphones.

No entanto, a maior parte das escolas, reconhecida como parte integrante da sociedade e de fundamental importância para a formação do indivíduo crítico e reflexivo, não faz uso destas tecnologias. Então, o que fazer para que essas tecnologias não sejam apenas um meio de transmissão de informações?

Encontramos em nossos levantamentos diversas discussões sobre a presença efetiva das atuais TICs associadas à prática pedagógica na escola e que trazem importantes questionamentos que contribuem para o desenvolvimento do presente artigo.

Estudos mostram que a presença das tecnologias, por si só, não garante que a aprendizagem ocorra (Almeida, 2006; Kenski, 2007). Mas, afinal, o que deve ser feito para que essas tecnologias possam contribuir efetivamente para a educação?

Uma possível resposta pode estar atrelada aos processos de formação de professores. De acordo com Almeida (2006), diversos projetos voltados principalmente para a formação de professores no uso crítico das tecnologias da informação e comunicação têm sido desenvolvidos com sucesso, embora ela ressalte que ainda está aquém do que se deseja.

Alguns problemas são centrais para que esses projetos não tenham o resultado esperado. Segundo Kenski (2007, p. 57), um dos problemas é a "falta de conhecimento dos professores para o melhor uso pedagógico da tecnologia, seja ela nova ou velha”. Isso se dá, principalmente, em função de um processo de formação do professor no qual o uso pedagógico das tecnologias não é parte integrante do currículo do ensino superior.

Ainda de acordo com Kenski (2007, p. 57), outro problema é a "não adequação da tecnologia ao conteúdo que vai ser ensinado e aos propósitos do ensino". Nesse sentido, é preciso compreender que cada tecnologia tem uma especificidade.

Para que ocorra a incorporação de tecnologias na prática pedagógica, não basta somente munir a escola de novos recursos tecnológicos, se faz necessário investir na formação de professores para que sejam capazes de utilizar criticamente esses recursos. De acordo com Kenski (2007):

Para que as TICs possam trazer alterações no processo educativo, no entanto, elas precisam ser compreendidas e incorporadas pedagogicamente. Não basta usar a televisão ou o computador, é preciso saber usar de forma pedagogicamente correta a tecnologia escolhida. (Kenski, 2007, p. 46) 
Normalmente, para fazer uso de um computador no processo educativo é necessário escolher um software educacional. Os Parâmetros Curriculares Nacionais de Matemática (Brasil, 1997), quanto aos softwares educacionais, orientam que é

[...] fundamental que o professor aprenda a escolhê-los em função dos objetivos que pretende atingir e de sua própria concepção de conhecimento e de aprendizagem, distinguindo os que se prestam mais a um trabalho dirigido para testar conhecimentos dos que procuram levar o aluno a interagir com o programa de forma a construir conhecimento (Brasil, 1997, p. 35).

Desse modo, o presente artigo tem por objetivo identificar, a partir das reflexões apresentadas por professores que ensinam matemática nos anos iniciais do ensino fundamental, as contribuições de um processo formativo pautado no modelo f@r focado no uso de softwares educativos (simuladores e jogos computacionais). Esse processo formativo foi desenvolvido por meio de um projeto aprovado ${ }^{1}$ no âmbito do Programa Observatório da Educação (OBEDUC), sendo estruturado segundo o modelo f@r: Formação-Ação-Reflexão, proposto por Costa (2012), o qual concebe cinco etapas, a saber: visão, plano, prática, interação e reflexão. Para atingirmos o objetivo proposto para o presente artigo, optamos por fazer um recorte focalizando a etapa de reflexão.

\section{Modelo f@ r: formação-ação-reflexão}

O modelo f@r (Costa, 2012) indica que o objetivo de um processo de formação é o de promover entre os professores e formadores, por meio da troca de experiências, um ambiente colaborativo e reflexivo sobre a integração das tecnologias no processo de ensino e aprendizagem.

É uma formação que se constrói por meio de um processo periódico e subjetivo, estruturado em cinco fases: Visão, Plano, Prática, Interação e Reflexão.

1. VISÃO - é o momento em que o professor deve responder as questões essenciais, como: Por que, para quê e como utilizar as tecnologias?

\footnotetext{
${ }^{1}$ Projeto: "Desafios para a Educação Inclusiva: pensando a formação de professores sobre os processos de domínio da Matemática nas séries iniciais da Educação Básica" aprovado no Programa Observatório da Educação (OBEDUC) da CAPES/INEP, edital 2010.
} 
2. PLANO - o professor decide, também com a ajuda dos formadores e colegas, as atividades que os alunos realizarão com recurso das tecnologias disponíveis na escola;

3. PRÁTICA - Constitui o momento em que as ideias incluídas são sujeitas à prova e as dificuldades emergem.

4. INTERAÇÃO - Espera-se precisamente que o professor interaja e discuta com o formador ou com os colegas sobre o processo e os resultados;

5. REFLEXÃO - O professor reflete individualmente sobre o modo como as atividades decorreram. (Costa, 2012, p. 98-99).

De acordo com o autor, esse modelo não ocorre necessariamente de maneira linear, ou seja, cada fase pode ser revisatada de acordo com as necessidades do grupo de formação.

A Figura 1, a seguir, ilustra as cinco etapas apresentadas com mais detalhes em Costa (2012):

Figura 1. Etapas e ciclo do trabalho do professor

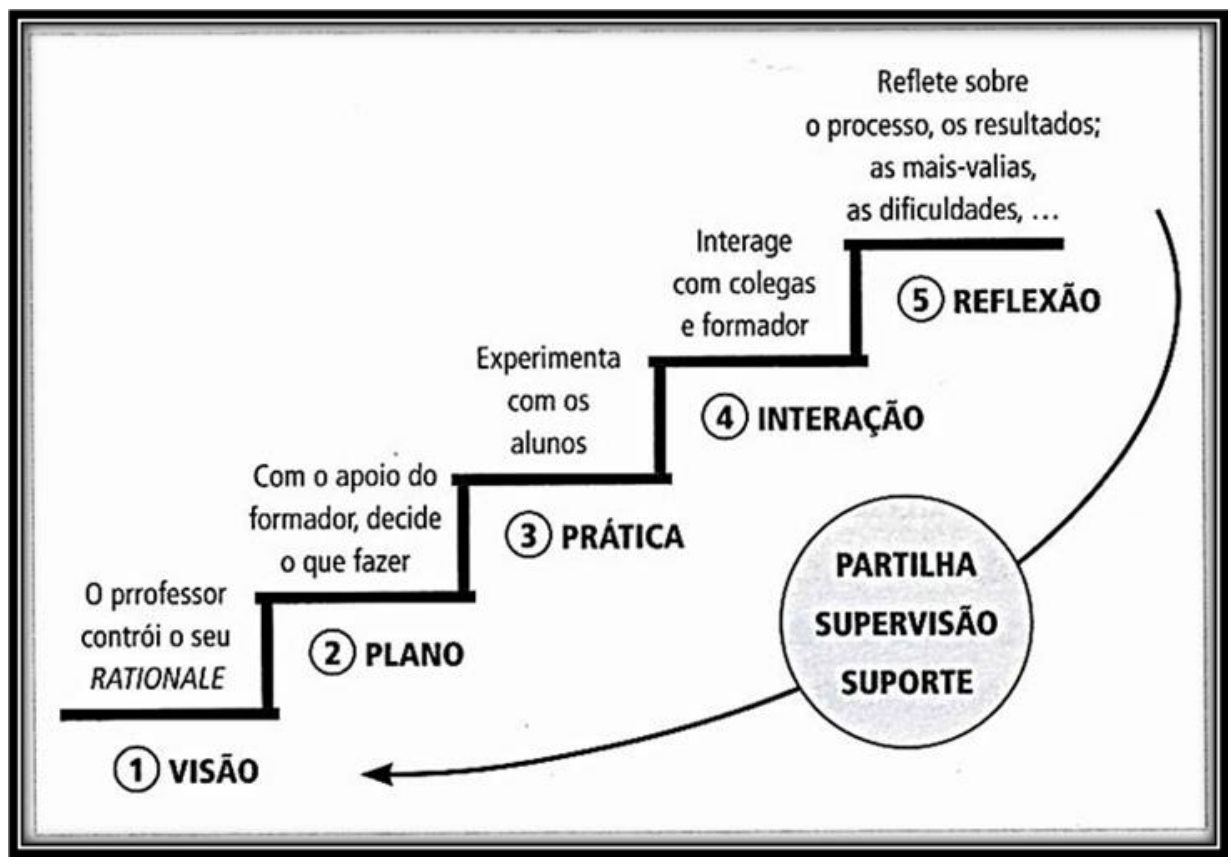

Fonte: Costa (2012, p. 98)

É possível verificar que o modelo f@r, conforme apresentado na figura 1, é concebido como um modelo de formação de professores que está mais direcionado para a realização de ações que podem ser oportunizadas em situações reais de discussão colaborativa e de sala de aula.

Para estruturação do modelo f@r, Costa (2012) apresenta algumas reflexões sobre alguns modelos de formação de professores com vistas à integração das tecnologias. Dessa maneira, 
especificamente acerca do Conhecimento Tecnológico e Pedagógico do Conteúdo - CTPC (TPACK) (Mishra, Koehler, 2006), a discussão apresentada por Costa (2012) contribui para a constituição do modelo f@r na medida em que identifica e orienta adequadamente sobre os conhecimentos necessários para que os professores possam desenvolver as habilidades e competências tecnológicas e pedagógicas necessárias para interiorizar e integrar as mais recentes tecnologias, em sua prática profissional de uma maneira crítica e reflexiva.

Em um determinado contexto de atuação do professor, o CTPC surge "quando o professor mobiliza em simultâneo o que sabe sobre tecnologias, sobre estratégias didáticopedagógicas e sobre o conteúdo científico definido no currículo" (Costa, 2012, p. 96), sempre tendo como objetivo utilizar esses conhecimentos integrados de tal forma que o conteúdo seja compreensível para os alunos.

Da mesma forma, acreditamos que o CTPC é construído durante a vida profissional, em que o professor possa desenvolver, retificar, ratificar e ampliar esse conhecimento mediante ações individuais e/ou coletivas.

Figura 2. Diagrama do Conhecimento Tecnológico e Pedagógico do Conteúdo (CTPC)

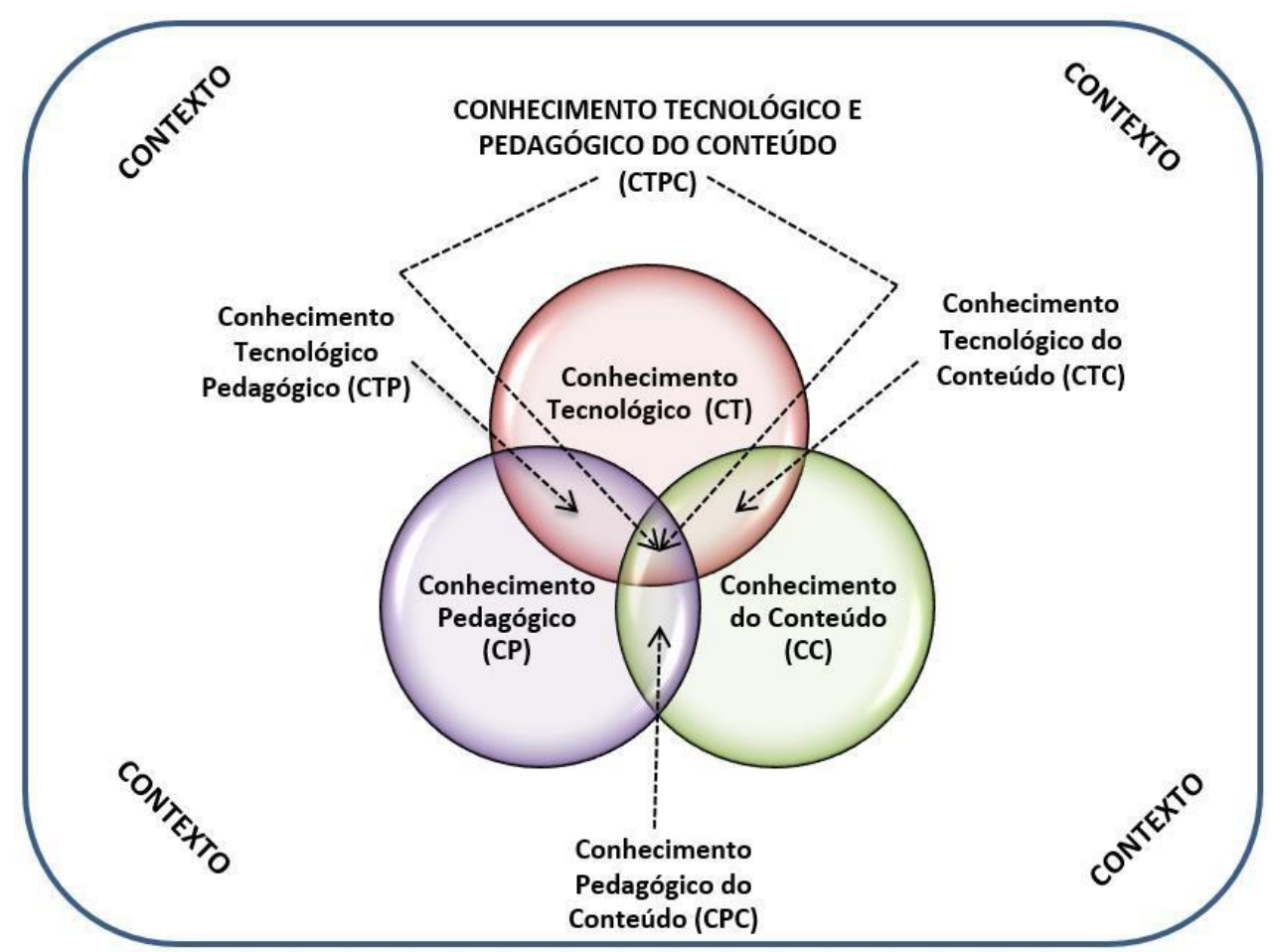

Fonte: Adaptado de Mishra e Koehler (2006)

De acordo com o diagrama apresentado na Figura 2, dado um determinado contexto, a partir da inter-relação do conhecimento do conteúdo (CC), conhecimento pedagógico $(\mathrm{CP})$ e 
conhecimento tecnológico (CT), podemos verificar que surgem novos conhecimentos. O já citado anteriormente, Conhecimento Pedagógico do Conteúdo (CPC) que surge da inter-relação do conhecimento do conteúdo e do conhecimento pedagógico. O Conhecimento Tecnológico Pedagógico (CTP) que resulta da inter-relação do conhecimento tecnológico com o conhecimento pedagógico. O Conhecimento Tecnológico do Conteúdo (CTC) que é resultado da inter-relação do conhecimento tecnológico com o conhecimento do conteúdo. E por fim, o Conhecimento Tecnológico e Pedagógico do Conteúdo (CTPC) que surge da inter-relação máxima dos três conhecimentos, conhecimento pedagógico $(\mathrm{CP})$, conhecimento do conteúdo (CC) e conhecimento tecnológico (CT).

Para que ocorra a integração das tecnologias no ambiente educacional, segundo Costa (2012), é necessário desenvolver uma Competência TIC que para ele é entendida como

[...] a possibilidade de mobilização de capacidades, conhecimentos e atitudes em situações de ensino e aprendizagem, em que o uso das tecnologias é relevante para resolver com sucesso os problemas aí suscitados (Costa, 2012, p. 87).

Sendo assim, uma questão colocada pelo autor é: quais as “competências que educadores e professores devem ter para serem capazes de interpretar e interiorizar o papel e o lugar das TIC na escola?" (Costa, 2012, p. 87).

Costa (2012) apresenta um referencial de macro competências TIC para que os professores possam integrar as tecnologias na educação. Para a análise deste trabalho organizamos as macro competências TIC, apresentadas por ele em duas categorias principais: "Formação na escola" e "Conhecimento Técnico". Essa organização se deu em função do que observamos durante o desenvolvimento do processo de formação proposto para o desenvolvimento desta pesquisa.

Para a categoria Formação na Escola selecionamos as macro competências TIC a serem desenvolvidas ou que já podem fazer parte do repertório pedagógico das professoras. São elas: a professora

- possui conhecimento atualizado sobre os recursos tecnológicos e seu potencial de uso educativo.

- acompanha o desenvolvimento tecnológico no que implica a sua responsabilidade profissional. 
- acessa, organiza e sistematiza a informação em formato digital (pesquisa, seleciona e avalia a informação em função de objetivos concretos).

- compreende vantagens e constrangimentos do uso das TIC no processo educativo e o seu potencial transformador do modo como se aprende. (Costa, 2012, p. 90)

Para a categoria Conhecimento Técnico selecionamos as seguintes macro competências TIC, a professora

- executa operações com hardware e software; observa regras de segurança no respeito pela legalidade e princípios éticos.

- executa operações com programas ou sistemas de informação online e/ou offline (acessa à internet, pesquisa em bases de dados ou diretórios, acessa a obras de referência, etc).

- comunica com os outros, individualmente ou em grupo, de forma síncrona e/ou assíncrona através de ferramentas digitais específicas.

- elabora documentos em formato digital com diferentes finalidades e para diferentes públicos, em contextos diversificados. (Costa, 2012, p. 90)

Além das macros competências anteriores, Costa (2012) também apresenta mais duas a seguir, mas que não serão foco da nossa discussão, pois não foram objeto de nossas análises, a professora

- conhece e utiliza ferramentas digitais como suporte de processos de avaliação e/ou de investigação.

- utiliza o potencial dos recursos digitais na promoção do seu próprio desenvolvimento profissional numa perspectiva de aprendizagem ao longo da vida. (Costa, 2012, p. 90)

Dessa forma, entendemos que para que aconteça uma integração e o consequente uso efetivo e consciente das tecnologias digitais na prática pedagógica, é fundamental que o professor assuma para si a responsabilidade de desenvolver a competência TIC necessária. 


\section{Percurso Metodológico}

O presente estudo foi realizado sob a perspectiva de uma metodologia de pesquisa qualitativa, do tipo observação participante (Creswell, 2010). Tal escolha se justifica pelo fato de os pesquisadores desempenharem, simultaneamente, o papel de investigador e participante.

$\mathrm{O}$ contexto em que os dados foram coletados emergiu de um grupo de formação estruturado a partir da aprovação de um projeto no âmbito do OBEDUC. Desse grupo, além dos pesquisadores, participaram cinco professoras que ensinam matemática nos anos iniciais do Ensino Fundamental em cinco escolas da rede pública da cidade de São Paulo - SP, sendo três de escolas municipais e duas de escolas estaduais.

Essas professoras, que possuem formações e trajetórias profissionais distintas, compartilham do mesmo desejo de complementar sua formação e buscar subsídios que possam contribuir para a melhoria de sua prática de sala de aula. Elas vislumbram, na participação em processos de formação como esse que propomos, encontrar respostas, compartilhar experiências, dúvidas, anseios e angústias relacionados à sua prática profissional.

Toda essa diversidade contribuiu para a constituição do grupo, tendo em vista que o compartilhamento é um dos fatores fundamentais para o desenvolvimento do processo de formação que propomos ao longo deste trabalho.

Apresentamos a seguir os passos do trabalho desenvolvido com as professoras. Estes passos englobaram as etapas propostas no referencial teórico que aprimoramos e foram utilizados na análise dos dados coletados.

- Pesquisa prévia sobre os softwares educativos disponíveis para o ensino de matemática nos anos iniciais do ensino fundamental;

- Estudo dos softwares educativos indicados pelas professoras;

- Seleção dos softwares educativos para a elaboração da atividade;

- Preparação das oficinas sobre o uso de softwares educativos no ensino de matemática;

- Interação com o grupo de formação para apresentação da atividade elaborada;

- Reflexão individual da professora sobre as contribuições dos outros professores acerca da validação e/ou reelaboração da atividade;

- Desenvolvimento de oficinas nas escolas;

- Reflexão conjunta com o grupo de professores sobre as oficinas. 
Os encontros do grupo serviram para: estudo e seleção de softwares educativos; preparação de atividades envolvendo o uso de softwares educativos para a realização de oficinas nas escolas envolvidas; interação e discussão em grupo sobre as atividades elaboradas; discussão e aprofundamento de alguns conteúdos matemáticos; e momentos de reflexão individual e conjunta.

Os softwares educativos trazidos pelas professoras foram: Poli, GeoGebra, além de CDs de jogos didáticos diversificados.

No entanto, os dados que compõem o presente artigo foram coletados por meio de observações e gravações em áudio e vídeo de dois encontros realizados em meados de novembro de 2013, dedicados ao movimento de reflexão conjunta, tal como previsto no modelo f@r (Costa, 2012). Durante o desenvolvimento deste trabalho, com o objetivo de garantir o anonimato das professoras, denominamos as professoras por P1, P2, P3, P4 e P5, tal como aprovado pelo Comitê de Ética² .

Ao pensarmos no grupo de formação que foi objeto desse estudo, é importante destacar que ele já estava constituído desde 2010 e tinha como característica principal, a diversidade. Já possuía uma identidade estruturada e um histórico consistente de participação no processo de formação em um espaço colaborativo.

Nesse sentido, verificamos que havia um ambiente favorável de discussão e colaboração, no qual as professoras se sentiam à vontade para o diálogo. Sobre a prática da formação, Imbernón (2010) traz algumas orientações que podemos identificar no nosso grupo de formação, entre elas destacamos:

Criar na formação um ambiente adequado para o debate, à troca e para a reflexão. Refletir e compartilhar com os professores as condutas educativas, as realizadas e as desejadas, para motivar o desenvolvimento de novas condutas. Compartilhar boas práticas. Estimular a experimentação de novas práticas educacionais e submetê-las ao debate. (Imbernón, 2010, p. 111).

\section{Análise da reflexão conjunta sobre o processo de formação}

\footnotetext{
2 Comitê de Ética em Pesquisa da PUC/SP, cadastrado na Plataforma Brasil, sob a aprovação ${ }^{\circ}$ CAAE 46243115.1 .0000 .5482 .
} 
Pelo fato de o presente artigo ser um recorte de uma pesquisa anterior (Farias, 2015), é importante salientar que, após o desenvolvimento das oficinas nas escolas, o grupo realizou uma avaliação do processo de formação daquele ano, por meio de uma reflexão conjunta, contemplando e complementando a última etapa do modelo f@r (Costa, 2012).

Nesse contexto, buscou-se identificar, a partir das reflexões apresentadas pelas professoras que ensinam matemática nos anos iniciais do ensino fundamental, as contribuições de um processo formativo pautado no modelo f@r focado no uso de softwares educativos (simuladores e jogos computacionais). Desse modo, destacamos na análise algumas falas que nos ajudam a atingir o objetivo proposto.

As professoras escolheram estudar alguns softwares educativos com vistas ao ensino da Matemática. Com base na seleção dos softwares feita pelas professoras percebemos que a mesma foi direcionada para os jogos computacionais. Entendemos que tal escolha teve como critério, além do ensino da Matemática, o aspecto lúdico que o jogo proporciona. Os softwares selecionados tinham como objetivo, o desenvolvimento da lógica, as quatro operações, números decimais e geometria plana.

Uma das contribuições que podemos destacar logo de início, quando da realização das oficinas nas escolas de São Paulo, é a percepção de alguns professores de que o horário de encontro coletivo para a formação dos professores, conhecidos como HTPC (Horário de Trabalho Pedagógico Coletivo) na rede estadual e JEIF (Jornada Especial Integral de Formação) na rede municipal, realizado no ambiente escolar, deveria ser realmente para uma formação continuada e coletiva dos professores. Durante o encontro, a professora P4 comenta a fala de uma professora de sua escola em relação à realização da oficina: "[...] o importante foi ouvir que o HTPC é isso aí. Até que enfim a gente teve o HTPC. Porque o HTPC é só para recados, avisos ou para chamar a atenção". (P4, Áudio do Encontro de Avaliação, 2013).

A relevância ao destacarmos esta fala consiste no fato de a professora $\mathrm{P} 4$ ter percebido que a oficina que conduziu teve relevância para os professores que participaram. Ao analisarmos o áudio da reunião de avaliação das oficinas, foi possível perceber que a professora P4 deu certa ênfase a essa questão, que demonstra que para ela foi importante ter seu trabalho reconhecido pelos demais professores. Esse reconhecimento tem o potencial de servir como fonte motivadora para que as professoras possam dar continuidade à realização de outras atividades coletivas na escola sobre o mesmo tema ou até mesmo sobre outros temas. 
Continuando com nossa análise, discorremos sobre a importância de o professor exercer o protagonismo na condução de um processo de formação na escola, bem como ter apoio da equipe de direção.

Algumas professoras revelaram a falta de apoio e incentivo para o desenvolvimento de ações formativas com os demais professores da escola. A professora P1 em sua resposta relata que:

Em relação à oficina, até comentei com ela (outra professora do grupo). Do grupo de direção ninguém apareceu lá. Eu marquei, eu que organizei tudo. Direção, nada. A coordenadora só falou professora P1 precisa da minha ajuda? Não, eu disse, pois sei que ela (coordenadora) é atribulada. Na verdade, a gente queria ajuda da direção. Mas tudo teve carta branca. (Pl, Áudio do Encontro de Avaliação, 2013).

Logo no início da resposta, já é possível perceber que a professora se sente à vontade em compartilhar sua frustração com a outra professora do grupo. Essa posição vai ao encontro de um dos aspectos que discutimos ao longo dessa pesquisa, que o professor, ao se propor participar de processos de formação em espaços colaborativos, deve estar aberto ao diálogo.

A professora P1 ao relatar que "marcou" o horário da oficina e "organizou tudo" demonstra que exerceu o seu protagonismo na preparação e realização da oficina. Contudo, avançando um pouco mais na resposta, ao afirmar categoricamente "Direção, nada", fica evidente que a professora P1 gostaria de ter apoio da equipe de direção, conforme afirma, avançando um pouco mais em sua resposta: "Na verdade a gente queria ajuda da direção".

Outro ponto que vale a pena destacar é quando a professora conta que, para a realização da oficina, "teve carta branca" para tudo. Isto é, de um lado a professora não conta com o apoio da equipe de direção, de outro, conta com a confiança da direção em relação ao seu trabalho como docente que contribui para a escola.

Já para a professora P3, essa experiência de apoio da equipe de direção foi diferente. A professora P3 responde que:

Como eu estava falando, lá na escola a diretora, as assistentes foram hipercordiais com vocês... Aí, assim, a gente fica à vontade em uma parte mais pedagógica, eles (equipe de direção) confiam no trabalho. (P3, Áudio do Encontro de Avaliação, 2013). 
A professora P3, ao relatar que a equipe de direção foi "hipercordial" conosco, demonstra, ainda que de uma forma não tão clara, que a sua participação no grupo de pesquisa, bem como a realização da própria oficina, teve boa aceitação para o grupo escolar. Tal aceitação acabou convertendo-se em um maior apoio da equipe de direção à professora na preparação da oficina. Esse apoio acabou contribuindo para que a professora P3 pudesse dar maior atenção, conforme ela mesma relata, a "uma parte mais pedagógica".

$\mathrm{O}$ apoio da equipe de direção, bem como de todos os envolvidos, contribui para o desenvolvimento de um processo de formação que seja significativo e que leve em conta os anseios e expectativas dos professores. Acrescenta-se ainda o fato de contribuir para que o professor tenha segurança.

Já a falta de apoio da equipe de direção acaba por criar obstáculos para o desenvolvimento de um processo de formação com qualidade, pois acaba sendo direcionada ao professor uma carga de trabalho intensa.

No entanto, verifica-se que, apesar de as professoras terem tido graus de apoio distintos à realização das oficinas, as professoras concordam que contaram com a confiança das respectivas equipes de direção.

Antes de prosseguirmos com nossa análise, cabe fazermos alguns esclarecimentos. Na escola da professora P1, a sala de informática que foi disponibilizada para a realização das atividades da oficina faz parte de um programa do governo do Estado de São Paulo, denominado Acessa Escola ${ }^{3}$. De acordo com as informações disponíveis no site Portal Acessa Escola:

Acessa Escola, um programa do Governo do Estado de São Paulo, desenvolvido pela Secretaria de Estado da Educação, sob a coordenação da Fundação para o Desenvolvimento da Educação (FDE), tem por objetivo promover a inclusão digital e social dos alunos, professores e funcionários das escolas da rede pública estadual. Por meio da Internet, ele possibilita aos usuários o acesso às tecnologias da informação e comunicação para a construção do conhecimento e o fortalecimento social da equipe escolar. (Portal Acessa Escola, 2008).

3 Tal programa foi instituído pela Resolução - SE - 37 de 25 de abril de 2008. Disponível em: <http://www.dersv.com/Res_SE_37_08_AcessaEscola.htm> acesso em 20 de janeiro de 2019. 
Após os esclarecimentos acima, seguimos com mais uma reflexão da professora P1 ao relatar um dos fatos que antecederam o início da oficina em sua escola. Ao ser informada, pelo responsável pela sala do Acessa Escola, que teria 2 horas para utilizar os computadores para a realização das atividades propostas na oficina. A professora P1 conta o que pensou naquele momento:

Aí planejava, bom até todo mundo chegar, $11 \mathrm{~h}$, até começar $11 \mathrm{hl}$, 11h15. Tenho que falar exatamente em 20 minutos, porque eu tinha feito um cronograma, avisei para a direção e coordenação. [...] Mas tudo deu certo. Dos onze funcionando, desligaram oito. (P1, Áudio do Encontro de Avaliação, 2013).

Mediante este relato é possível perceber que a professora P1 estava com tudo planejado. Ainda assim, mesmo com tudo planejado, houve alguns contratempos que dificultaram o início das atividades. As oficinas foram realizadas em dois momentos, no primeiro, com uma apresentação de slides pelas professoras sobre o software educativo utilizado. E o segundo momento, com a realização das atividades utilizando o jogo nos computadores disponíveis nas respectivas escolas.

$\mathrm{Na}$ escola da professora P1, a apresentação do software educativo foi realizada em um auditório, ao finalizar a apresentação, nos dirigimos à sala do Acessa Escola, porém demorou um pouco até encontrar a pessoa que estava com a chave da sala. Além disso, durante a realização das atividades, a maioria dos computadores desligou conforme relatou a professora P1. Como a própria professora declara, apesar dessas dificuldades, as atividades ocorreram conforme previsto, o que se confirma em sua frase: “tudo deu certo". Após o relato e as reflexões da professora P1, a professora P2 faz o seguinte comentário:

Posso fazer uma crítica para o Estado? Não é para você não... (referindo-se a professora P1). Mas, como eles querem que vocês usem o computador com o aluno se o computador desliga em duas horas? (P2, Áudio do Encontro de Avaliação, 2013).

Esse comentário é relevante, pois mostra o quão foi e é importante o compartilhamento de experiências em grupos de formação coletiva como esse que propomos. O relato da professora P1 acabou favorecendo o grupo no sentido de provocar a reflexão sobre as condições limitadoras impostas para o uso dos computadores nas escolas. 
A professora $\mathrm{P} 1$ durante a reflexão conjunta relatou que já tinha trabalhado com alguns jogos disponíveis em sites. Já as respostas das professoras P2 e P5 revelam uma realidade ainda existente em muitas escolas.

Nas escolas municipais o uso da sala de informática tem algumas restrições: os jogos que podem ser usados devem ser autorizados. Por isso, temos poucos jogos. (P2, Questionário 1, 2013)

Eu ainda não utilizo porque as aulas de informática são dirigidas pelo professor da disciplina e a sala (de computadores) não fica disponível para uso em outras aulas. Apenas por isso! Eu adoraria trabalhar com estes recursos se os computadores estivessem disponíveis. (P5, Questionário 1, 2013).

Essas respostas mostram que nas escolas há alguns fatores que funcionam como obstáculos para que ocorra o uso dos recursos computacionais, por exemplo, restrições de acesso ao uso de computadores e da sala de informática, somente alguns jogos podem ser utilizados, em muitos casos não é permitido ao professor instalar jogos no computador etc.

Verifica-se também que a sala de informática é direcionada somente para ser utilizada por um professor especialista da área de informática educacional. Essas dificuldades acabam desmotivando o professor quanto ao uso de softwares educativos e, consequentemente, das tecnologias disponíveis na escola. Não podemos deixar de mencionar que essas questões apareceram durante as discussões realizadas nos encontros de formação e puderam ser observadas quando da realização das oficinas nas escolas.

Até aqui foi possível verificar que o professor das escolas públicas pesquisadas tem o seu acesso limitado aos recursos tecnológicos disponíveis na escola. Convém destacar que não somos contra o monitoramento e controle dos recursos disponíveis no espaço escolar, pois, em nossa perspectiva o monitoramento e controle devem servir para que ocorra o uso consciente e responsável dos recursos disponíveis. O que nos incomoda é o fato de tal monitoramento e controle às vezes ser excessivo, servindo como uma barreira que pode acabar desmotivando o uso desse valioso recurso por parte do professor.

Dessa maneira, identificamos algumas contribuições que as reflexões coletivas realizadas nesta etapa proporcionaram à formação continuada das professoras em relação ao uso de software educativos. Identificamos as seguintes contribuições: 
- o reconhecimento de que as oficinas contribuíram e possibilitaram que o horário de encontro coletivo para formação dos professores fosse realmente para a formação continuada;

- a percepção que as professoras tiveram ao notarem que o seu trabalho teve relevância e contribuiu para a compreensão do uso das TICs pelos demais professores;

- o reconhecimento da importância de o professor exercer seu protagonismo;

- o movimento de reflexão que foi proporcionado ao se discutir sobre a questão do apoio da equipe de direção para o desenvolvimento de projetos envolvendo TICs na escola;

- o compartilhamento de experiências, proporcionado por intermédio das oficinas que promoveram um ambiente favorável ao diálogo entre as professoras; e

- o movimento de reflexão das professoras ao questionarem sobre a infraestrutura disponível nas escolas.

Miskulin (2003) considera que uma formação reflexiva e coerente de professores para o uso das tecnologias, na sociedade atual, é fundamental para uma ação educativa coerente. Essa coerência está no sentido de que o professor pode contribuir para uma formação de um indivíduo crítico, reflexivo, e que atenda aos anseios da sociedade atual em que vivemos, onde as inovações e informações são processadas rápida e continuamente em nível global.

Sendo assim, não há como pensar em uma integração coerente e produtiva das mais recentes tecnologias na educação, sem antes pensar na formação de professores para que possam integrar essas tecnologias de maneira crítica e reflexiva em sua prática pedagógica. De outra forma, continuaremos presos a métodos de ensino e teorias que, no contexto atual, já não contribuem para a formação autônoma dos indivíduos na utilização de novas maneiras de gerar e dominar o conhecimento.

Discorrendo especificamente sobre a presença da tecnologia no ensino da matemática, Miskulin (2003, p. 7) chama a atenção para o fato de que o professor que vai ensinar matemática com o subsídio da tecnologia, reflita sobre a sua utilização, levando em conta que a "Matemática, no contexto tecnológico, torne-se um caminho que possa superar as desigualdades sociais e ainda possibilitar a formação e a inserção adequada do sujeito a uma sociedade permeada pela tecnologia". 
Costa e Lins (2010) concordam que a presença das tecnologias na escola tem exigido uma nova postura do professor frente ao seu uso. Postura essa que exige que o professor tenha necessariamente autonomia para explorar o potencial pedagógico dessas tecnologias. Nesse sentido, entendemos que já não é mais suficiente que o professor tenha os conhecimentos básicos de como se opera determinada tecnologia. É fundamentalmente necessário que o professor tenha conhecimentos concretos que permitam que ele utilize efetivamente essa tecnologia como mediadora efetiva da construção do conhecimento do conteúdo que está ensinando.

Entendemos, então, que o movimento de reflexão ocorrido nos encontros contribuiu para que os professores, mesmo que em níveis diferentes, realizassem a construção-consolidaçãomobilização de conhecimentos tecnológicos pedagógicos, favorecendo a integração das tecnologias da informação e comunicação em sua prática profissional.

Além disso, podemos argumentar que a análise dos dados coletados nos possibilitaram compreender que o contexto estabelecido por esse processo de formação possibilitou que cada uma das professoras do grupo, em diferentes níveis, desenvolvesse em simultâneo, o que sabiam sobre tecnologias, sobre as estratégias pedagógicas e sobre o conhecimento de determinado conteúdo. Percebemos, então, a articulação dos elementos que compõem o referencial CTPC: o conhecimento do conteúdo, o conhecimento pedagógico e o conhecimento tecnológico. Os resultados mostraram também que os encontros de formação possibilitaram que as professoras pudessem compartilhar o que sabiam e o que não sabiam sobre cada um dos conhecimentos propostos no referencial CTPC. Esse compartilhamento contribuiu para a construção coletiva de um Conhecimento Tecnológico e Pedagógico do Conteúdo, passando a ser um conhecimento coletivo e individual.

\section{Considerações finais}

Identificamos que as atividades realizadas durante os encontros de formação, o estudo dos softwares educativos, as discussões e a preparação das oficinas também contribuíram para que as professoras vivenciassem na prática, o momento coletivo e individual de formação-açãoreflexão, conforme o modelo f@r (Costa, 2012). Sob esse ponto de vista, as professoras, durante os encontros de formação, puderam expor suas dúvidas e percepções sobre o uso das tecnologias 
atuais, tanto em nível pedagógico como pessoal. Acrescenta-se a isso, que o trabalho em grupo despertou nas professoras um sentimento de pertencimento.

Verificamos que esse processo de formação que propomos, estabeleceu um contexto no grupo de formação que possibilitou que as professoras mobilizassem os seus conhecimentos pedagógicos sobre determinado conteúdo matemático por meio dos conhecimentos tecnológicos construídos e/ou em construção. Percebemos que as professoras, ao prepararem as atividades, considerando a utilização dos recursos tecnológicos mais atuais, também passaram a adquirir uma perspectiva mais sólida sobre os conhecimentos que já possuíam sobre determinado conteúdo matemático.

Percebemos que, independentemente dos problemas que encontramos durante esse processo formativo, o que deve ser destacado é o empenho, a força de vontade de cada uma das professoras para que as oficinas fossem realizadas da melhor maneira possível.

Além disso, acreditamos ser um equívoco considerar que somente a inserção das atuais tecnologias da informação e comunicação no ambiente escolar e, mais especificamente, em sala de aula, resolva todos os problemas de ensino de Matemática. Antes disso, é de fundamental importância se pensar no processo de formação de professores que vão ensinar Matemática. E essa formação deve ir ao encontro dos anseios da sociedade em relação aos novos meios de comunicação e produção de conhecimento.

Considerando o atual cenário tecnológico que se impõem a toda sociedade e, consequentemente, a educação, é fundamental repensar e redimensionar os cursos de formação de professores (Miskulin, 2003), para que esses cursos contribuam para que os professores possam, efetivamente, construir conhecimentos e ações que atendam a essa nova demanda na educação com vistas à integração e ao avanço das tecnologias.

Contudo, compreendemos que é necessário que os cursos de formação de professores, tanto inicial quanto continuada, repensem suas matrizes curriculares para que a utilização das tecnologias mais recentes sejam partes integrantes nas discussões e possibilitem aos professores refletirem sobre a efetiva integração dessas tecnologias em sua prática pedagógica, objetivando a construção e consolidação de conhecimentos matemáticos.

Com base nos dados coletados e nas análises realizadas, e considerando que vivemos em uma sociedade em que a tecnologia está muito presente no nosso dia-a-dia, entendemos que já não cabe mais pensar em uma educação que esteja inerte a esse avanço tecnológico. Já não é 
mais suficiente uma educação centrada exclusivamente na utilização do giz e lousa como representantes exclusivos de tecnologias. Além disso, a pouca presença da tecnologia na escola acaba contribuindo para que essa instituição seja pouco atraente para os alunos, pois ainda é uma das poucas instituições da nossa sociedade atual que ainda não integrou efetivamente as tecnologias em seu ambiente. Dessa forma, a escola continua refém de métodos tradicionais de ensino que já não atendem integralmente e a contento, os anseios da sociedade em que vivemos.

\section{Referências}

ALMEIDA, M. E. B. (2006). Inclusão Digital do Professor: formação e prática pedagógica. São Paulo: Articulação. 234p.

BRASIL. (1997). Parâmetros curriculares nacionais: matemática. Secretaria de Educação Fundamental. - Brasília: MEC/SEF.

COSTA, F. A. et al. (Coord.). (2012). Repensar as TIC na educação: O professor como agente transformador. Carnaxide: Santillana. 143p.

COSTA, M. L. C.; LINS, A. F. (2010). Trabalho colaborativo e utilização das tecnologias da informação e comunicação na formação do professor de Matemática. Educação Matemática Pesquisa, São Paulo, v. 12, n. 3, p. 452-470, set./dez. Disponível em: $<$ http://revistas.pucsp.br/index.php/emp/article/view/4509/3719>. Acesso em: 13 nov. 2013.

CRESWELL, J. W. (2010). Projeto de Pesquisa: métodos qualitativo, quantitativo e misto. 3 ed. Porto Alegre: Artmed. 296p.

FARIAS, F. D. (2015). Uso de softwares educativos para o ensino de Matemática: contribuições de um processo de formação de professores dos anos iniciais do ensino fundamental. 108 f. Dissertação (Mestrado em Educação Matemática) - Programa de Estudos Pós-Graduados em Educação Matemática. Pontifícia Universidade Católica. São Paulo.

IMBERnÓN, F. (2010). Formação Continuada de Professores. Porto Alegre: Artmed, 2010. $120 \mathrm{p}$.

KENSKI, V. M. (2007). Educação e Tecnologias: O novo ritmo da informação. 2 ed. Campinas: Papirus.

MISHRA, P. \& KOEHLER, M.J. (2006). Technological Pedagogical Content Knowledge: A Framework for Teacher Knowledge. Teachers College Record, 108(6), 1017-1054

MISKULIN, R. G. S. (2003). As possibilidades didático-pedagógicas de ambientes computacionais na formação colaborativa de professores de Matemática. Disponível em: <http://www.pucrs.br/famat/viali/tic_literatura/artigos/ava/Miskulin_Rosana.pdf>. Acesso em: 07 de abril de 2014. 